\title{
WYBRANE ASPEKTY TAOISTYCZNEJ PRAKTYKI WÉIWÚWÉI
}

\author{
Wacław Romer, e-mail: waclawromer@gmail.com \\ Uniwersytet Wrocławski \\ Pl. Uniwersytecki 1, 50-137 Wrocław
}

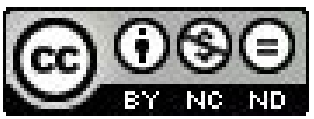

\section{STRESZCZENIE}

Artykuł ma na celu zbadanie wybranych aspektów zalecanej przez Dàodéīng praktyki wéiwúiwéi (為無為) poprzez spojrzenie na nią w różnych kontekstach. Postawionych jest pięć tez: (1) w Dàodéjing czytamy o ontologicznej zasadzie głoszącej, że funkcjonalność bytu jest konstytuowana przez jego strukturę będącą niebytem; (2) wéiwuízwéi może być realizowane jako inspiracja przykładem; (3) wéizuírwéi może być realizowane jako efekt transcedentalnej bądź psychologicznej transformacji podmiotu polegającej na wyzwoleniu sprawstwa z uwarunkowań; (4) wéizuízéi może być realizowane jako przyzwolenie na błędy podwładnych; (5) proponowany przez Dàodéjing ideał władcy charakteryzuje nis ka preferencja czasowa.

Słowa kluczowe: wuwei, weiwuwei, dao, taoizm, anarchizm, wychowanie, nieruchomy poruszyciel

\section{Some aspects of the taoist practice wéiwúiwéi}

\begin{abstract}
The article aims to explore some aspects of the wéiwúwéi (為無為) practice recommended by the Dàodéjing by examining it in various contexts. Five theses are postulated: (1) we read in the Dàodéjing about an ontological principle which states that the functionality of the entity is determined by its structure which is a nonentity; (2) wéiwúwéi can be performed by inspiring by personal example; (3) wéiwúwéi can be realized as a result of a transcendental or psychological transformation of the subject by liberating the agent from conditions; (4) wéiwúwéi can be performed as permission for the errors of one's subordinates; (5) The ideal ruler as proposed by the Dàodéjing is characterized by low time preference.
\end{abstract}

Key words: wuwei, weiwuwei, dao, daoism, upbringing, anarchism, unmoved mover

\section{WSTĘP}

Poniższy artykuł jest próbą wyłonienia z Dàodéjīng i zbadania niektórych aspektów praktyki wéizuíwéi (為無 為), to jest działania przez niedziałanie. Traktat przypisywany Lăozi ma przede wszystkim charakter polityczny. Aż czterdzieści rozdziałów związanych jest z polityką. Ponadto, odnosi się do niej aż sześć z dwunastu passusów dotyczących zasady wúwéi. Dlatego też głównie w tym kontekście będę prowadził analizy. W toku rozważań postawię pięć tez interpretacyjnych. Rozpocznę bardziej ogólnymi uwagami dotyczącymi ontologicznych treści traktatu, które stanowią fundament dla wúzwéi (無為).

\section{Ontologia}

Trzydzieści szprych połaczonych w piaście tworzy koło. W piaście nic nie istnieje (無) - dzięki temu istnieje (有) zastosowanie (用) dla koła. Ścianki naczynia formuje się z gliny. Pomiędzy ściankami nic nie istnieje - dzięki temu istnieje zastosowanie dla naczynia. Ściany z otworami na okna idrzwi tworza dom. Pomiędzy ścianami nic nie istnieje - dzięki temu istnieje zastosowanie dla domu. Dlatego zarazem byt (有) przynosi korzyści i niebyt (無) jest użyteczny (用)1. [rozdział XI]

Powyższy cytat jest egzemplifikacją i zarazem metaforą ontycznych zasad. Zarówno byt, jak i niebyt, przynosi korzyść. Jaką? Zastosowanie przedmiotu, jego naturę, czyli jego funkcję w akcie, zaktualizowaną możność, potencjał, grecki ergon. Istotnie, to sposób połączenia elementów domu jest odpowiedzialny za jego funkcjonalność. Kontynuując grecką analogię, możemy powiedzieć, że sposób połączenia to nic innego jak struktura, arystotelesowski eidos.

\footnotetext{
1 Lăozi, Księga dao i de z komentarzami Wang Bi, Kraków 2006, s. 42.
} 
Lăozi jednak kładzie nacisk na niebyt. W komentarzu Aleistra Crowleya do tego rozdziału czytamy:

Materia jest niczym ograniczajace plan linie. Plan jest realny, a niezwykle mate wzolędem niego linie stuża jedynie jego zdefiniowaniu ${ }^{2}$.

Crowley proponuje spojzzenie odwrotne do zgodnego z potoczną intuicją. Dla niego pustka jest realna, zaś eidos konstytuowany jest przez jej przeciwieństwo - materię. Nie musimy przyjmować jego kontrowersyjnej propozycji, lecz zgódźmy się na zasadę: forma determinowana jest przez przeciwieństwo bytu. Wang Bi konstatuje:

Te trzy [koło, naczynie i dom] zostaty wykonane odpowiednio z drewna, gliny i cegiet, lecz pożytek z nich plynacy zależy od tego, czego nie ma. To znaczy, że to, czego nie ma, warunkuje użyteczność rzeczy³.

Widać więc, że niebyt pełni rolę nadrzędną wobec bytu. Możliwe są zatem dwa rozwiązania: 1) ergon przedmiotu jest warunkowany przez eidos, który jest ukonstytuowany niebytem 2) ergon przedmiotu warunkowany jest przez pewne jądro struktury, które jest konstytuowane przez skoncentrowane zagęszczenie niebytu w przedmiocie. Widać wyraźnie, że druga możliwość jest wariantem pierwszej. Nazwę pierwsze rozwiązanie zasadą uży te c zności i postawię pierwszą tezę: w Dàodéjing czytamy o zasadzie użyteczności.

\section{DiagnOza WSTĘPNA}

Wúwwéi najczęściej tłumaczy się jako niedziałanie, a wéiwúiwéi jako działanie przez niedziałanie. Alex Feldt wymienia następujące tłumaczenia tych terminów: nieczynność (nonactivity), (nie) robienie niczego (doing nothing), nieprzymuszające działanie (non-coercing action) niewarunkujące (non-conditioning), nienarzucające (non-imposing), bez premedytacji (unpremeditated), nierozmyślne (nondeliberative), niewyrachowane (noncalculating), niecelowe (nonpurposive action) i najbardziej popularne: niedziałanie (non-action); nieprzymuszanie (noncoercion), nieprzymuszająca czynność (noncoercive activity), działanie bez wysiłku (effortless action), działanie naturalne (acting naturally).

Pamiętając o zasadzie użyteczności, można pojać wéíwúrwéi jako takie działanie, którego jądro ustanowione jest przez skoncentrowane niedziałanie. Jednak, jak zauważa Aleksandar Stamatov ${ }^{5}$, wúiwéi nie jest też tożsame z absolutną pasywnościa, bezczynnościa, niezrobieniem, bùzwéi (不為). Wręcz przeciwnie, w rozdziale XXXVII czytamy:

Dào jest wieczne i nie działa (無為). Tym samym nie ma nic, co nie zostałoby niezrobione (不為) ${ }^{6}$.

Wúwéi wiąże się więc z wúbìzwéi (無不為), stanem, gdy „nic nie zostało niezrobione”, gdzie „niezrobione” (undone) oznacza "niedomknięte”, „niedokończone”. Wéiwuízwéi ma zatem na celu wúbùweéi. Wéiwúiwéi jest zatem działaniem skutecznym, który definitywnie kończy potrzebę dalszego działania. Gdy panuje wúbìzwéi mamy wúrwéi. Wúwéi jest zatem środkiem i celem wéíuíwéi.

Doskonałym przykładem wéiwuíwéi w praktyce jest japońskie zapaśnictwo. Pisze o tym Julius Evola, cytując Carla Puiniego: „nie należy nigdy przeciwstawiać siły sile; zamiast tego, trzeba przewrócić przeciwnika, obracając jego własną siłę przeciw niemu" ${ }^{\prime \prime}$. Oczywiście działanie przeciw komuś jest tutaj jedynie przykładem, równie dobrze można nakierować energetyczny prąd ku czyjejś korzyści.

\section{TRWAJĄC, WPRAWIAĆ W RUCH}

Aby zrozumieć kolejny aspekt wéíwúiwéi, pojmę działanie jako zmianę, ruch. Wéiwúiwéi rozumiane jest wtedy jako nieruchome poruszanie. Nie chodzi tutaj o bezwzględny bezruch. Chodzi o bezruch względny w odniesieniu do poruszanego przedmiotu w izolowanym układzie. Na poziomie etycznym przykładem takiego zachowania jest inspirowanie działaniem zgodnym z własną naturą. W takim wypadku inspirujący nie wykonuje ruchu w kierunku inspirowanego. Działa zgodnie z własną natura, niezależnie od tego czy potencjalnie inspirowany będzie odbierał inspirację czy nie.

2 A. Crowley, Tao Te Cing, Gdynia - Londyn 2007, s. 36.

3 Lăozi, dz. cyt, s. 42 .

4 A. Feldt, dz. cyt, s. 331.

5 A. Stamatov, The Laozi and Anarchism, „Asian Philosophy: An International Journal of the Philosophical Traditions of the East” 2014, No 3, s. 265 .

6 Lăozi, dz. cyt, s. 82 .

7 J. Evola, Taoism. The Magic, The Mysticism, Sequim 2006, s. 17. 
Stwierdziłem, że za przykład wéíwúiwéi rozumianego jako nieruchome poruszanie można uznać poruszanie mocą własnego przykładu, inspirowanie. Podobnego zdania jest Max Cafard, gdy twierdzi, że „anarchiczne »bez rządzenia» oznacza, że powinniśmy wpływać na świat przez naszą drogę życia i osobisty przykład”" ${ }^{\prime \prime}$ Z kolei John Clark pisze, że potęga władcy „pochodzi tylko z mocy samego przykładu“" . Jest to tylko spekulacja, Dàodéjing nie daje w tym względzie jednoznacznej wytycznej. Można jednak wysunąć takie przypuszczenie. Postawię więc drugą tezę: wéiwúwwéi może być realizowane jako inspiracja przykładem. Czytamy, że mędrzec-władca:

Nieustannie dba o to, by ludzie byli bez wiedzy (無知) i bez pragnień (無欲 ${ }^{10}$. [rozdział III]

Lecz jednocześnie:

\section{Nie perswaduje, dlatego przekonuje11. [rozdziat XXII]}

Wúzhī (無知) analogicznie do wúw wéi nie jest absolutną niewiedza, głupota, lecz „,wiedzą nieuzasadnioną”, właściwą wiedzą „, dé (德) rzeczy", czyli o ich wewnętrznym charakterze, cnocie. Podobnie wúnyù (無欲) nie jest brakiem pragnienia, lecz „pragnieniem bez swego przedmiotu”, pragnieniem bez przywiązania ${ }^{12}$. Zarówna wúzhī jak i wúyù są atrybutami mędrca. Ma on bowiem:

\section{Kochajac ludzi - rzadzić krajem; umieć nie stosować wiedzy (無知)! ${ }^{13}$ [rozdział X]}

Dalej zaś Dàodéjing instruuje:

\section{Jeśli pragnienia (欲) się obudza, unieruchomie je $e^{14}$. [rozdział XXXVII]}

Widać zatem, że zadaniem mędrca jest wykształcenie własnych cech w poddanych. A. Stamatov pisze: „wízwéi oznacza ekspansję porządku z góry do dołu i wúzhī oraz wúyù są wynikiem zgodnego z wúiwéi postępowania władcy"15. Zarządca nie używa jednak perswazji, zgodnie z przywołanym wcześniej cytatem. Nie zmusza on też nikogo siłą. Byłoby kuriozalne, gdyby szantaż fizyczny był zgodny z duchem wíwéi, a perswazja już nie. Wang Bi komentuje cytowany passus z rozdziału trzeciego następująco: „mędrca chroni to, że naprawdę jest sobą"16. Pozwala to uwiarygodnić tezę inspiracji. Inspiracji subtelnej, naturalnej, podczas której inspirujący nie wykonuje żadnego ruchu w kierunku inspirowanego, a jedynie realizuje swoją naturę, pozostając sobą.

Choć zadaniem cesarza będzie nacechowanie ludu wízhī i wúyù, to wúzwéi pozostanie zarezerwowane dla władcy. Zdaniem A. Stamatova , jest to podstawowa zasada sprawstwa władcy i nie jest to coś wymaganego od zwykłych ludzi" ${ }^{\prime \prime}$. Wúzwéi w pełni swego znaczenia jest wynikiem transformacji podmiotu, która jest udziałem jedynie nielicznych. Nieruchome intencjonalne oddziaływanie podmiotu na przedmiot zawsze wiąże się z pewnym immanentnym ruchem podmiotu, takim jak ruch myśli czy ruch emocji. Aby zrozumieć, czym jest nieruchome poruszanie, można skorzystać z analizy emicznej. Według J. Evoli wúiwéi „,oznacza niedziałanie tylko ze strony peryferyjnego ego"18 oraz „wybór nie umieszczania się na tym samym planie sił lub rzeczy, które chcemy kontrolowac' ${ }^{\prime \prime 1}$. Widać tutaj opozycję planów. Pierwszy plan to transcendentalne Ja, centrum podmiotu, nieuwarunkowane. Na zupełnie innym planie leży "punkt ciężkości" podmiotu, kompozyt myśli, emocji, wrażeń: empiryczne Ja, ego. Z perspektywy ego, transcendentalne Ja jest nieuchwytne, niewyrażalne, ponieważ to transcedentalne Ja jest tym, co chwyta, wyraża, intenduje. Stąd jego deskrypcja ma charakter apofatyczny. Centrum względem ego jest nicością. Jednak to ono stanowi jądro podmiotu, jest odpowiedzialne za jego funkcjonalność. Centrum bowiem intenduje. Wszelkie uwarunkowania leżą poza centrum, gdzie znajduje się ego, skąd

8 M. Cafard, The Surre(gion)alist Manifesto \& Other Writings, Baton Rouge 2003, s. 35.

9 J. Clark, Master Lao and the Anarchist Prince, https://www.academia.edu/2540539/_Master_Lao_and_the_Anarchist_Prince_ 31.12.2014

10 Lăozi, dz. cyt, s. 30 .

11 Tamże, s. 60.

12 A. Stamatov, dz. cyt., s. 268.

13 Lăozi, dz. cyt, s. 40.

14 Tamże, s. 60.

15 A. Stamatov, dz. cyt., s. 269.

16 Lăozi, dz. cyt, s. 31 .

17 A. Stamatov, dz. cyt., s. 268.

18 J. Evola, dz. cyt., s. 15.

19 Tamże, s. 17. 
zazwyczaj wychodzą decyzje. W tym ujęciu działanie, yìwéi (欲為) będzie polegało na decydowaniu z planu uwarunkowanego, a wúzwéi na braku tegoż. Wéiwúiwéi polega na decydowaniu z samego tylko centrum, z nieuwarunkowanej pustki. Aby to osiągnąć, centrum musi zinternalizować ego, „punkt ciężkości” podmiotu, ośrodek sprawczy podmiotu (sprawca, spełniacz aktów) musi przesunąć się w nieuwarunkowane ${ }^{20}$. Postawię zatem trzecią tezę: wéiwúiwéi może być realizowane jako efekt transcendentalnej bądź psychologicznej transformacji podmiotu polegającej na wyzwoleniu sprawstwa z uwarunkowań. J. Evola pisze:

Ten, kto jest przyczyna i rzeczywistym panem ruchu, sam się nie porusza. Inspiruje on ruch i kieruje dziataniem, lecz nie działa, w tym sensie, iz nie jest poruszany, nie jest zwiazany z akcja, nie jest działaniem, lecz niewzruszona, całkowicie spokojna i rozkazujacc wyższościa, od której wywodzi i na której opiera się akcja²1.

Podmiot, który zinternalizował ego w swoje centrum, jest greckim ho ou kinoúmenon kinê̂, nieruchomym poruszycielem. Charakteryzuje się całkowitym samoopanowaniem, nic nie ma nad nim władzy, wyemancypował swoją wolę z wszelkich ograniczeń, działa bez wysiłku. Jak pisze J. Evola:

Nigdy nie identyfikuje się z zewnętrzną rzeczywistością. Nigdy nie działając bezpośrednio, nie eksternalizuje swojego ego przez afirmację siebie, zamiast tego aktywnie wyrzeka się „,bycia” i „działania” w sposób bezpośredni i uwarunkowany. Doskonały osiąga to, co jest naprawdę istotne. W ten sposób staje się niewyczerpywalny, nietykalny i niepodatny na dowolne zewnętrzne próby ujarzmienia go i uczynienia go bezsilnym, zależnym. Na mocy takiego procesu Doskonały może działać w sposób subtelny, niewidzialny sposób: to jest sens wyrażenia wéíwúiwéi ${ }^{22}$.

\section{DOJRZEWAĆ w BURZACH}

Aspekt inspiracyjny wéiwúiwéi nasuwa skojarzenia z wychowaniem. Roger Ames twierdzi, że taoizm „postrzega państwo jako naturalną instytucję, analogiczną być może do rodziny"23. Tom Hodgkinson w swojej książce Być rodzicem i nie skonać. Rodzicielstwo na luzie proponuje wúzwéi jako metodę wychowawczą i łączy ją z metodą Jeana-Jacques'a Rousseau, Johna Locke'a i Davida Lawrence'a. Ja jednak pochylę się nad jedną z najbardziej renomowanych i uniwersalnych metod wychowania o zasięgu światowym, metodzie skautowej opracowanej w 1908 r. przez Roberta Baden-Powella. Zarysowuje on dychotomię między nauczaniem a wychowaniem. W tym drugim, właściwym, kluczowy jest aspekt inspiracyjny. Według niego „nauczanie jest niczym w porównaniu z przykładem”24. W metodzie R. Baden-Powella wychowywaniem kilkunastoletnich chłopców zajmuje się drużynowy, około osiemnastoletni chłopak. We Wskazówwach dla skautmistrzów czytamy o nim:

Chtopcy szybko dostrzega jego najmniejsza ceche charakterystyczna, czy to będzie zaleta czy wada. Przyswoja sobie jego sposób zachowania, a grzeczność, jaka okazuje, jego rozdrażnienie, stoneczna pogoda czy niecierpliwe uniesienia, jego silna dyscyplina wewnętrzna, czy przypadkowe potknięcia - to wszystko jest nie tylko zauważone, ale i skrzętnie naśladowane ${ }^{25}$.

Jak się okazuje, metoda skautowa koresponduje z Dìodéjing. Czytamy we Wskazówkach:

Praca drużynowego podobna jest do gry w golfa, do cięcia sierpem, lub do łowienia ryb na wędkę. Nie uda się, gdy będziemy się spieszyć26.

Tymczasem w rozdziale LX Lăozi mówi nam:

Rzadzenie wielkim panstwem podobne jest do przyrzadzania potrawy z matych rybek ${ }^{27}$.

20 J. Evola nazwał to „miejsce” „nadświadomością” w kontraście do Jungowskiej nieświadomości. Zob.: J. Evola, O istocie Zen, http://tradycjonalizm.net/juliusevola/zen.htm, 31.12.2014.

21 J. Evola, Na antypodach modernizmu, Biała Podlaska 2014, s. 40. Fragment ten nie dotyczy bezpośrednio taoizmu, lecz idei nieruchomego poruszania, która zdaniem J. Evoli jest wspólna wielu tradycjom filozoficznym i religijnym oraz występuje także w taoizmie.

22 Tenże, Wei-Wu-Wei \& Lao Tsu's Ultimately Aristocratic Notion of Non-Action, http://www.juliusevola.net/excerpts/Wei-Wu-Wei_\%26_Lao_ Tsus_Ultimately_Aristocratic_Notion_of_Non-Action.html, 31.12.2014.

23 R. Ames, Is political Taoism anarchism?, "Journal of Chinese Philosophy" 1983, No10 (1), s. $27-47$ [cytat za:] A. Stamatov, dz. cyt., s. 270.

24 R. Baden-Powell, Wskazówki dla skautmistrzów, Warszawa 1991, s. 53.

25 Tamże, s. 11.

26 Tamże, s. 12

27 Lăozi, dz. cyt, s. 121. 
Co Wang Bi: komentuje następująco:

Mędrzec niczego nie przyśpiesza i nie wprowadza nerwowej krzataniny, która szkodzi. (Jeśli smaży się małe rybki i często się je przeworaca z jednej strony na druga, rozpadaja się) $)^{28}$.

Ewidentna obecna tu będzie również zasada użyteczności i duch wúiwéi, którym metoda skautowa jest przeniknięta. Drugim kluczowym elementem Baden-Powellowskiego wychowania jest obarczenie odpowiedzialnością wychowanków, co oznacza, że ideałem jest gdy drużynowy nie czyni nic, poza obserwacją i dyskretnymi sugestiami. W idealnej drużynie wszystkimi zadaniami kierują odpowiedzialni za nie jego podopieczni zastępowi.

Nie rób nigdy sam tego, co chtopcy powinni wykonać, dopilnuj jedynie, by oni to wykonali - ,jeśli chcesz by coś byto zrobione, nie rób tego sam" - oto wtaściwa tu zasada $a^{29}$.

Myśla przeewodnia systemu zastępowego jest zasada nałożenia rzeczywistej odpowiedzialności na możliwie największa ilość chłopców, celem rozwoju ich charakteru. Jeżeli drużynowy powierza zastępowemu prawdziwą władze, wymagajac wiele od niego i pozostawiajac mu wolna rękę w wykonywaniu pracy, uczynit więcej dla rozwinięcia charakteru chtopca niz̈by mogło uczynić jakiekolwiek nauczanie szkolne ${ }^{30}$.

Metoda skautowa polega na całorocznym przygotowywaniu się do momentu kulminacyjnego - obozu. Osiagalną perfekcją w skautingu, ostatecznym sukcesem drużynowego jest stan, kiedy obóz przygotowany jest całkowicie przez wychowanków $w^{31}$. Wszystkie elementy i momenty obozu, takie jak miejsce, logistyka transportu i zaopatrzenia, zbudowanie konstrukcji, wybór i przyrządzenie żywności oraz organizacja gier realizowane są wtedy przez kilkunastoletnie dzieci, a drużynowy jedynie subtelnie trzyma pieczę nad kierunkiem całego procesu. Z perspektywy skautów wygląda to jednak tak, jakby byli zupełnie niezależni w swoich działaniach. To, co się wtedy dzieje, koresponduje z rozdziałem XVII Dàodéjing:

Jeśli Wielki Człowiek jest na szczycie, ci, którzy sa na dole, wiedza tylko, że on istnieje.....)

Jego dzieło wieńczy sukces, ludzie mówwią stało się tak samo z siebie (自然)32.

Lăozi i Baden-Powell wykazują też zbieżność celów. W Dàodéjing jest mowa o de, immanentnym charakterze rzeczy i ludzi, cnocie, której dojrzewanie postępuje dzięki wúwéi, a zakłócane jest przez yùzwéi. Jak zauważa Clark, taoistyczny świat przenika dào (道): harmonia konstytuowana przez kompleks samorealizacji poszczególnych bytów, z których każdy posiada immanentny telos ${ }^{33}$. Realizacja własnego Dào, to uczestnictwo w uniwersalnym dào.

$z$ dào (道) sa narodziny,

a z dé (德) jest wzrost, dorastanie, opieka i pokój.

Rodzić, lecz nie brać w posiadanie.

Działać, lecz nie uzależniać od siebie;

Pobudzać wzrost, lecz nie sprawować władzy.

To się nazywa tajemnym dé (德) ${ }^{34}$. [rozdziat LI]

Wskazówki... pouczają natomiast:

Charakteru nie można wmusztrować w chłopca. Zarodek jego tkwi w chłopcu, wymaga jednak wydobycia i rozwinięcia35.

Zarysowana analogia pozwoli postawić tezę dotyczącą mechanizmu tego aspektu wéíwúiwéi. Według Baden-Powella „podopieczny popełniając błędy zdobywa doświadczenie i kształtuje swój charakter" ${ }^{\prime \prime 36}$. Analogicznie w przypadku wúzwéi mielibyśmy do czynienia z p rzy z w ole ni em na błęd y. Postawię więc czwartą tezę: wéiwúiwéi może być reali-

\footnotetext{
28 Tamże.

29 R. Baden-Powell, dz. cyt, s. 82.

30 Tamże, s. 54.

31 Tamże, s. 81.

32 Lăozi, dz. cyt, s. 52.

33 J. Clark, dz. cyt.

34 Lăozi, dz. cyt, s. 106.

35 Baden-Powell, dz. cyt, s. 47.

36 Tamże, s. 16.
} 
zowane jako przyzwolenie na błędy podwładnych. Przy takim postawieniu sprawy, różnica między działaniem przez yùzwéi, a działaniem przez wúzwéi polega na tym, że w tym pierwszym podmiot nakierowany jest na doraźną korzyść, mającą charakter tymczasowy, natomiast $\mathrm{w}$ drugim przypadku chodzi o wykształcenie dyspozycji zapewniającej trwałą korzyść w przyszłości. Yùzwéi, zapewniając tymczasową korzyść, uniemożliwia jednak samorealizację i tym samym stwarza konieczność dalszego działania w przyszłości. Rozwiązując problem, kreuje drugi, w dodatku większy, będąc tym samym Derridowskim farmakonem. Z kolei ten, który działa przez wúzwéi, wykazuje się myśleniem długofalowym. Teraźniejszość satysfakcji z rozpatrywanej korzyści jest dla niego względnie mało ważna. Preferuje on późniejszą długotrwałą satyfakcję nad obecna, lecz krótkotrwałą. W ekonomii mówi się, że kogośtakiego charakteryzuje ni s ka pr ef e r e n cja c z a s o w a ${ }^{37}$. Postawię tutaj piątą tezę: proponowanego przez Dàodéjing idealnego władcę cechuje niska preferencja czasowa. Niech jej dodatkowym potwierdzeniem będzie poniższy cytat:

\section{Czynić dojrzatym, nie zarzadzać. To się nazywa tajemnicza biegłością? ${ }^{38}$ [rozdział X]}

Warto tutaj zaznaczyć, że niska preferencja czasowa nie ma żadnego z związku z ciągłą antycypacja „ż̇yciem w przyszłości". Obie postawy są oczywiście możliwe do zrealizowania jednocześnie w jednym podmiocie. Przywołując wcześniejsze rozważania, "życie w przyszłości" polegałoby na sytuowaniu się punktu ciężkości podmiotu w antycypacjach (ewentualnie w p r o te n cja ch, jeśli mamy na myśli odmienny przypadek nieustannego pośpiechu donikąd). Jak zobaczyliśmy wcześniej, nie jest to przypadek mędrca.

\section{Anarchizm}

Prawdopodobnie wciąż najbardziej popularną interpretacją politycznej wykładni Dìodéjing (a także Zhuāngžl), pozostaje anarchizm. Jednym z pierwszych, który powiązał go z taoizmem, był konfucjański uczony Liang Qichao ${ }^{39}$. John Clarke stwierdził, że „stało się niemal banałem, żeby utożsamiać te dwa" ${ }^{\prime 00}$. Jednym z najczęściej przywoływanych cytatów dotyczących tej kwestii jest twierdzenie A. C. Grahama, że „zachodni anarchiści utrzymywali, że Lăozi jest jednym z nich, pomimo że jego książka została poznana na zachodzie w XIX wieku" ${ }^{\prime 41}$. Richard Sylvan wyjaśnia, że „są znaczące antycypacje anarchizmu we wcześniej filozofii (szczególnie w stoicyzmie i taoizmie)"42. Podobnie Andrew Vincent zauważa, że „twierdzi się także, że anarchistyczne motywy są do odnalezienia w starożytnych chińskich tekstach takich jak Dàodéjing" ${ }^{\prime \prime}$. W $1980 \mathrm{r}$. w Bostonie odbyło się sympozjum pod tytułem "Czy polityczny taoizm jest anarchistyczną teorią" i jego owocem był „ogólny konsensus, że taoistyczna myśl jest w najwyższym stopniu anarchistyczna" ${ }^{\prime \prime 4}$. John P. Clark posunął się jeszcze dalej i stwierdził, że „żadna znacząca filozoficzna praca czy to Wschodu czy Zachodu nie była tak gruntownie przeniknięta anarchistycznym duchem" ${ }^{\prime \prime 4}$.

Obszerną i usystematyzowaną analizę większości argumentów za i przeciw anarchistycznej interpretacji przedstawił A. Stamatov w artykule The Laozi and Anarchism. Sam autor jednak nie opowiedział się po żadnej ze stron, a tutaj nie mamy miejsca na streszczanie wszystkich przesłanek.

A. Feldt opowiada się stanowczo przeciw anarchistycznej interpretacji. W artykule A Non-Anarchistic Interpretation of the Laozi wysuwa trzy argumenty ${ }^{46}$ : (1) Dèodéjing jest politycznym traktatem adresowanym do władcy. Czterdzieści rozdziałów ma polityczny charakter. Wúwéi pojawia się w tekście dwanaście razy, z czego aż sześć jako polityczna technika. W tekście wielokrotnie pojawia się wątek państwa w kontekście jego zarządzania, np. w rozdziałach XXIX, LVII czy LX. Co więcej, zdaniem A. Feldta w rozdziale XVII mamy do czynienia z pełną akceptacją państwa. (2) Starożytna chińska koncepcja ludzkiej osoby jest niezgodna z klasycznym zachodnim anarchizmem. Zachodni anarchizm wychodzi od atomistycznego pojęcia jednostki. Ja pojmowane jest jako autonomiczne i dyskretne. $\mathrm{W}$ takim ujęciu wola jednostki będzie

37 H. Hoppe, Demokracja - bóg, który zawiódt, Warszawa 2006, s. 32.

38 Lăozi, dz. cyt., s. 40.

39 A. Stamatov, dz. cyt., s. 264.

40 J. Clarke, Taoist Politics: An Other Way?, [w:] F. Dallmayr (red.), Border Crossings: Towards a Comparative Political Theory, Lanham 1999, s. 260, [cytat za:] A. Feldt, dz. cyt., s. 323.

41 A. Graham, Disputers of the Tao: Philosophical arguments in ancient China, La Salle 1989, s. 299 [cytat za:] A. Stamatov, dz. cyt., s. 260.

42 R. Sylvan, Anarchism, [w:] P. Robert, E. Goodin (red.), A companion to contemporary political philosophy, Oxford 2007, s. 257 [cytat za:] A. Stamatov, dz. cyt., s. 260.

43 A. Vincent, Modern political ideologies, Oxford 1992, s. 116 [cytat za:] A. Stamatov, dz. cyt., s. 260.

44 A. Feldt, dz. cyt., s. 325.

45 J. Clark, dz. cyt.

46 A. Feldt, dz. cyt., s. 327. 
w nieustannym napięciu względem woli wyróżnionej grupy i na tym napięciu są budowane anarchistyczne roszczenia. Z kolei taoizm pojmuje Ja jako współzależne i skontekstualizowane. Jednostka jest częścią skontekstualizowanej sieci relacji. Nie można więc na niej oprzeć anarchistycznych pretensji. Ponadto, zdaniem A. Feldta taka koncepcja implikuje pewną dozę przymusu obecną pomiędzy rządzonym a rządzącym. Skoro i tak są oni wyjściowo współzależni jako elementy tej samej sieci relacji, to bez istnienia przymusu rozróżnienie na rządzonego i rządzącego traci sens. (3) Anarchistyczny obiekt krytyki jest różny od taoistycznego. Dàodéjing wymierzone jest przeciw konfucjańskiemu stylowi rządzenia, a nie przeciw rządzeniu jako takiemu. Co więcej, w rozdziale XVII konfucjański władca nie jest przedstawiony jako najgorszy, lecz jedynie jako gorszy od taoistycznego.

A. Feldt ostatecznie stwierdza, że polityczny taoizm najlepiej koresponduje z minarchistycznym libertarianizmem Roberta Nozicka, koncepcją państwa minimalnego jako „nocnego stróża”. Na taką koncepcję przystanąłby pewnie anarchokapitalista Murray Rothbard, który nazwał Lăozi „pierwszym intelektualistą libertarianinem” ${ }^{\prime \prime 7}$ (a dopiero Zhuāngž̆ miałby być dla niego "być może pierwszym anarchistą w świecie”). Max Weber nazwał polityczną propozycję taoizmu „chińskim manczesteryzmem". Co ciekawe, za wolnorynkową interpretacją Dàodéjing optowali też Ronald Reagan ${ }^{48}$ oraz Slavoj Žižek ${ }^{49}$. Ja przystaję na leseferystyczne ujęcie. Fundamentem mojego stanowiska jest teza o niskiej preferencji czasowej władcy. Koresponduje ona z koncepcją ła du na tu raln e go ekonomisty Hansa-Hermanna Hoppego, którą przedstawia w książce Demokracja, bóg który upadł. Ład naturalny miałby być wolnorynkową koegzystencją wielu społeczności, z których dominowałyby te przewodzone przez elity o niskiej preferencji czasowej. Stąd można mówić, że jest to koncepcja względnie anarchistyczna. Zbiór relacji pomiędzy owymi społecznościami miałby być izomorficzny względem zbioru relacji zachodzących pomiędzy współczesnymi panstwami. Według H. Hoppego systemy polityczne związane z przymusem można nanieść na skalę rozpiętą między bezwzględną monarchią a bezwzględną demokracją. Jak apriorycznie wykazuje: z im bardziej demokratycznym systemem mamy do czynienia, tym bardziej na objętym przezeń obszarze obniżają sięk rzy we prefe re n cji cz a so w ej, czyli wskaźniki zależności s to py prefer en cji cza sow ej od realnego dochodu pieniężnego jednostki. Owocuje to zdehumanizowaniem działan wojennych, zanikiem tradycyjnych wartości, wzrostem przestęp czości, wszechobecną bylejakościa, nieodpowiedzialnością i wzrostem biurokracji. W związku z tym myśl Hoppego, choć anarchistyczna, jest paradoksalnie pro-monokratyczna, co koresponduje z analogiczną pozorną sprzecznością wyłaniającą się z Dàodéjing .

\section{Podsumowanie}

W tym artykule postawiłem pięć tez: (1) w Dàodéjing czytamy o ontologicznej zasadzie, głoszącej że funkcjonalność bytu jest konstytuowana przez jego strukturę będącą niebytem. Praktyka wéiwúiwéi opiera się na tej zasadzie; (2) wéizuízwéi może być realizowane jako inspiracja przykładem; (3) wéíwúiwéi może być realizowane jako efekt transcedentalnej bądź psychologicznej transformacji podmiotu polegającej na wyzwoleniu sprawstwa z uwarunkowań. Co istotne, mamy do czynienia z sugestia, że jest to kondycja dostępna nielicznym i pożądana tylko u nielicznych; (4) wéiwúrwéi może być realizowane jako przyzwolenie na błędy podwładnych; (5) proponowany przez Dàodéjing ideał władcy charakteryzuje niska preferencja czasowa. Co ważne, nie oznacza to ciagłego antycypującego intendowania. Ponadto twierdzę, że polityczna wykładnia Dàodéjing koresponduje z koncepcją ładu naturalnego zaproponowaną przez H. Hoppego. Postawione tezy nie mają charakteru historycznego. Stanowią interpretację omawianej księgi, pewną propozycję odczytania, bardziej filozoficzno-spekulatywna, niż religioznawczą.

47 M. Rothbard, Concepts of the Role of Intellectuals in Social Change Toward Laissez Faire, "The Journal of Libertarian Studies" 1990, No 2, s. 44.

48 New York Times, 1/26/88, [informacja za:] M. Cafard, dz. cyt., s. 33.

49 S. Žižek postrzega fenomen zachodniego taoizmu jako komplementarną reakcję na ducha globalnego korporacyjnego kapitalizmu. Zob.: P. Bowman, The Tao of Žižek, [w:] P. Bowman, R. Stamps (red.), The Truth of Žižek, London 2007. 


\section{TEKSTY ŹRÓDŁOWE:}

[1] Lăozi, Ksiegga dao i de z komentarzami Wang Bi, tłum. Wójcik A., Kraków 2006.

\section{Bibliografia:}

[2] Ames R., Is political Taoism anarchism?, ,JJournal of Chinese Philosophy" 1983, No 10 (1).

[3] Baden-Powell R., Wskazówwi dla skautmistrzóww, Warszawa 1991.

[4] Bowman P., Stamps R. (red.), The Truth of Žižek, London 2007.

[5] Cafard M., The Surre(gion)alist Manifesto \& Other Writings, Baton Rouge 2003.

[6] Ching J., Mysticism and kingship in China, Cambridge 1997.

[7] Clarke J., Taoist Politics: An Other Way?, [w:] Dallmayr F. (red.), Border Crossings: Towards a Comparative Political Theory, Lanham 1999.

[8] Crowley A., Tao Te Cing, Gdynia-Londyn 2007.

[9] Evola J., Na antypodach modernizmu, Biała Podlaska 2014.

[10] Evola J., Taoism. The Magic, The Mysticism, Seqium 2006.

[11] Feldt A., Governing Through the Dao: A Non-Anarchistic Interpretation of the Laozi, „Dao: A Journal of Comparative Philosophy” 2010.

[12] Graham A., Disputers of the Tao: Philosophical arguments in ancient China, La Salle 1989.

[13] Hodgkinson T., Być rodzicem i nie skonać. Rodzicielstwo na luzie, Warszawa 2013.

[14] Hoppe H., Demokracja - bóg, który zawiódt, Warszawa 2006.

[15] Rothbard M., Concepts of the Role of Intellectuals in Social Change Toward Laissez Faire, „,The Journal of Libertarian Studies" 1990, No 2.

[16] Stamatov A., The Laozi and Anarchism, „Asian Philosophy: An International Journal of the Philosophical Traditions of the East” 2014 , No 3.

[17] Sylvan R., Anarchism, [w:] Robert P., Goodin E. (red.), A companion to contemporary political philosophy, Oxford 2007.

[18] Vincent A., Modern political ideologies, Oxford 1992.

[19] Weber M., Etyka gospodarcza religii - tom 1. Taoizm i konfucjanizm, Kraków 2000.

[20] Zarrow P., Anarchism and Chinese Political Culture, New York 1990.

\section{Netografia:}

[21] Clark J., Master Lao and the Anarchist Prince, https://www.academia.edu/2540539/_Master_Lao_and_the_Anarchist_Prince_ 31.12.2014.

[22] Evola J., O istocie Zen, http://tradycjonalizm.net/juliusevola/zen.htm, 31.12.2014.

[23] Evola J., Wei-Wu-Wei \& Lao Tsu's Ultimately Aristocratic Notion of Non-Action, http://www.juliusevola.net/excerpts/Wei-Wu-Wei_\%26_Lao_ Tsus_Ultimately_Aristocratic_Notion_of_Non-Action.html, 31.12.2014. 